\title{
Navigating Assigned Roles for Asynchronous Online Discussions: Examining Participants' Orientation Using Conversation Analysis
}

\author{
Amber N. Warren \\ Professional Specialized Studies, University of Nevada, Reno
}

\begin{abstract}
Asynchronous computer-mediated communication (CMC) tools, such as asynchronous online discussions (AODs), are widely used in higher education. The organization of AODs is of pedagogical importance, particularly for online-only classes, as these discussions are one of the major opportunities for participants to develop understanding of course content. This study examines participant orientation to a common AOD practice, assigning roles. The data were gathered from a graduate-level teacher education course that used forum discussion module included in Sakai. Using a conversation analytic perspective, data were examined to understand patterns in participants' uptake of Discussion Starter and Devil's Advocate roles in the forum. The findings demonstrate how assigning roles established a frame for participants' understanding of course content and delimited possibilities for participation. Further, patterns of engagement related to these roles encouraged participants to distance themselves epistemically from the content of their posts. Specifically, students took up the Devil's Advocate role in both expected and unexpected ways. While students did use this role as an opportunity to disagree with others in the forum, they also took up the role of Devil's Advocate to pose non-critical questions. Pedagogical insights and the usefulness of conversation analysis as an analytical approach are discussed.
\end{abstract}

Keywords: distance education, online learning, asynchronous discussion, higher education, computer-mediated communication, conversation analysis

Warren, A.N. (2018). Navigating assigned roles for asynchronous online discussions: Examining participants orientation using conversation analysis. Online Learning, 22(4), 27-45. doi: 10.24059/olj.v22i4.1512

Navigating Assigned Roles for Asynchronous Online Discussions: Examining Participants' Orientation Using Conversation Analysis

Despite the increasing use of synchronous modes of communication in distance education courses (e.g., web-conferencing), online education still relies heavily on asynchronous computermediated communication (CMC) tools, such as blogs or discussion forums, with asynchronous online discussion (AOD) widely used in higher education. Research indicates that AODs can offer valuable opportunities for student reflection (Krutka et al., 2014; Levin, He, \& Robbins, 2006) and that interaction in forums can be important for creating meaningful dialogue (Swan \& Shea, 2005) and engaging learners cooperatively (Hmelo, Guzdial, \& Turns, 1998). However, scholarship has 
also frequently noted the challenge in creating the type of meaningful dialogue promised by AODs (Stahl, Cress, Ludvigsen, \& Law, 2014).

One common practice used to remedy this challenge is assigning roles for participants to enact. These roles, such as Discussion Starter or Devil's Advocate, are designed to increase student engagement (Hara et al., 2000; Olesova, Slavin \& Lim, 2016). Assigning roles, as with any educational mediation, affects how participants interact during the discussions. However, most of what we know about assigned roles in AODs comes from frameworks designed to assess increases in students' knowledge (e.g., Swan \& Shea, 2005; Weinberger \& Fischer, 2006). These studies often emphasize researcher-created categories, rather than accounting for what the participants themselves do in the interaction (Lamerichs \& te Molder, 2003).

Recently, scholars have posited the value of examining the uptake of these roles from the perspectives of the students themselves (e.g., Wise, Saghafian, \& Padmanabhan, 2012; Wise \& Chiu, 2013). Relatedly, many have recognized the value of using language-oriented approaches such as discourse analysis to study online talk (e.g., Brooks, 2013), in some instances in concert with existing theories of online interaction (e.g., Goertzen \& Kristjánsson, 2007). These scholars note the value of using language-based approaches to make sense of how participants themselves select to interact with one another within online class discussion forums. Additionally, scholars have demonstrated how conversation analysis (CA) offers a useful, participant-driven approach for analyzing online talk as it unfolds (Meredith, 2017).

Following these observations, this paper uses CA to examine participants' uptake of assigned discussion roles, namely those of Discussion Starter and Devil's Advocate. To explore how participants negotiated and discursively managed these assigned roles, analysis was focused on the sequential ordering of participants' posts. This study was conducted in order to understand the potential that such role assignments have as a frame for discussion, with the aim of better informing instructional practices for AODs in online classes.

\section{Background}

This study examines participants' uptake of role positions in asynchronous online classes. Literature reviewed focuses on research regarding AODs, particularly studies focused on the use of assigned roles. It also describes studies that have used discourse or conversation analytic approaches to understand online interaction, as this provides necessary background to understand the potential of these approaches for investigating such issues.

\section{Discussion in Asynchronous Online Classes}

Research suggests that AODs offer opportunities for both engagement and reflection, as they leave time for students to think before they react. For example, it has been found that teacher candidates in online courses build community (Hou, 2015; Tseng \& Kuo, 2014), reflect on their practice (Jones \& Ryan, 2014; Whipp, 2003), pose clarifications (Fisch \& Bennett, 2011) and develop deeper understanding through questioning (Williams et al., 2016). On the other hand, researchers have sometimes identified challenges to achieving meaningful discussion or making connections between knowledge and theory, especially in unmoderated forums (Ben-Peretz \& Kupferberg, 2007). Ravenna and colleagues (2012), similarly found that AODs could promote student engagement, but only when the discussions were carefully designed and moderated. Killeavy and Moloney (2010) found that AODs among beginning teachers did not often result in analysis or reflection on problems, instead typically remaining focused on immediate challenges. 
Mixed findings on the ability of forums to promote meaningful discussion have led some researchers to suggest that providing students with guidelines for discussion is an essential element of instruction (e.g., Yuan \& Kim, 2014). Research has suggested that assigning roles creates mutual accountability for participants (Strijbos et al., 2004), and creates opportunities for ownership of learning (Tagg, 1994). Assigning specific roles in the discussion further impacts interaction patterns (Xie, Yu, \& Bradshaw, 2014) and may even increase students' engagement or cognitive presence (Hara et al., 2000; Olesova, Slavin, \& Lim, 2016).

While the use of discussion roles has been popular in online instruction, other studies have suggested that role assignments, and the responsibilities allotted to these roles, are not consistently assigned with regard to their individual function (Wise, Saghafian, \& Padmanabhan, 2012). Wise et al. (2012) investigated the functions of common role descriptions and how successfully these roles were performed by learners. The researchers found that some roles were more accurately fulfilled by students, but that all roles were valued. Still others have argued that to better understand the effects that different directions for discussion interactions have on learning, researchers need to attend to how these models situate the "locus of control" (Loncar, Barrett \& Liu, 2014, p. 103). In a review of 43 studies of AOD, Loncar and colleagues argued that using "prompts, scaffolding structure, and discussion strategies, either through methods or new tools or environments, significantly weights locus-of-control, as well as autonomy, towards the forum system and instructor, and away from students, peers and learners" (p. 104). Shifting attention away from students is a concern also held by CA researchers, who focus on endogenous participant perspectives.

To date, only a few studies have examined participants' orientation to these roles within the discussions themselves. Wise, Speer, Hsaio, and Marbuti (2013) examined individual participation patterns in an undergraduate blended course. Using microanalysis, they analyzed log files and post contents and found that students' participation patterns aligned with theoretical taxonomic participation patterns developed by Knowlton (2005). They argued that a microanalytic lens, though limited due to the researchers' access only to log-files, was useful in understanding students' actions within the discussion forums. Xie, Yu, and Bradshaw (2014) used social network analysis to examine the interaction patterns of students in an online class. They found that students in the moderator role significantly increased their participation quantity and diversity, and that their non-participation also had a significant influence on group interactions. Wise and Chiu (2014) studied the role of summarizer in online discussions. They found that while evidence for participants' depth of "listening" increased slightly during the week a student was assigned to the role, post-role weeks showed reduction in participants' review of posts, thus suggesting unintended consequences of role assignments. This paper takes up a microanalytic lens (e.g., Wise et al., 2012) to understand how students orient to two assigned discussion roles: the role of Discussion Starter and that of Devil's Advocate (provocateur), the latter of which has not yet been investigated from a microanalytic approach.

\section{Using CA to Study Online Interaction}

The analytical goal of conversation analysis (CA) is "to describe the intertwined construction of practices, actions, activities, and the overall structure of interaction" (Stivers \& Sidnell, 2013, p. 2). CA was originally developed in the 1960s by Harvey Sacks, Gail Jefferson, and Emmanuel Schegloff $(1974,1992)$ out of ethnomethodology (Garfinkel, 1967). CA research is marked by its distinctive, microanalytic approach to the analysis of participant interactions. That is, CA research focuses on the moment-to-moment conversational choices of participants in a 
given interaction. For example, a CA researcher might focus on how surprise tokens (e.g., "wow") function to display affiliation or membership within a particular group (Wilkinson \& Kitzinger, 2006). In CA, the focus of analysis is on the sequential organization of talk, which is recognized as significant to making meaning both for participants and analysts (Schegloff, 2007). This central tenet of CA orients the researcher to how participants' talk accomplishes particular actions "by virtue of their placement and participation within sequences of actions" (Heritage, 1984, p. 245). In other words, CA researchers are interested in how turns at talk are organized, and how talk is organized within an individual turn, including how it is oriented to accomplishing something within a given interaction.

Though traditionally applied to the study of synchronous communication, in the $1990 \mathrm{~s}$, scholars began exploring the applicability of CA for the study of quasi-synchronous and asynchronous communication (e.g., Baym, 1996; Hutchby \& Tanna, 2008). For example, scholars applying CA to CMC have investigated the role of technology in Skype (Rintel, 2010) and the affordances that Facebook chat provides (Meredith, 2017). Thus, while the extent to which all features of face-to-face talk might be applied to understand online discussion is still under examination, the study of online interaction using CA, or "digital CA" is increasing (Giles et al., 2015).

In an overview of CA as used to study interactional practices and dynamics as they arise online, Paulus, Warren, and Lester (2016) found that there have been four main aims within online research using CA, including: the comparison of face-to-face and online talk; the study of how coherence is maintained online; understanding how participants deal with interactional issues when they arise; and, a focus on how participants accomplish social actions in asynchronous environments. The current study is situated within this final group of studies, as it is focused on how participants accomplish social actions as they take up assigned roles in online class discussion. Further, data from the present study would be classified as "conversation-like data" (Giles et al., 2015 , p. 45, original emphasis) in that the participants may choose one (or more) participants as the addressee of their posts, as well as use the physical organization of the discussion forum as de facto sequence organization, as in Figure 1. In this figure, the respondent begins their reply to the previous participant stating, "in response to your third point." The use of the generic possessive pronoun "your" makes evident the addressee. The possessive pronoun use, coupled with the physical collocation of this post as directly following the previous post, make the sequential organization visible within the affordances of the forum software. 


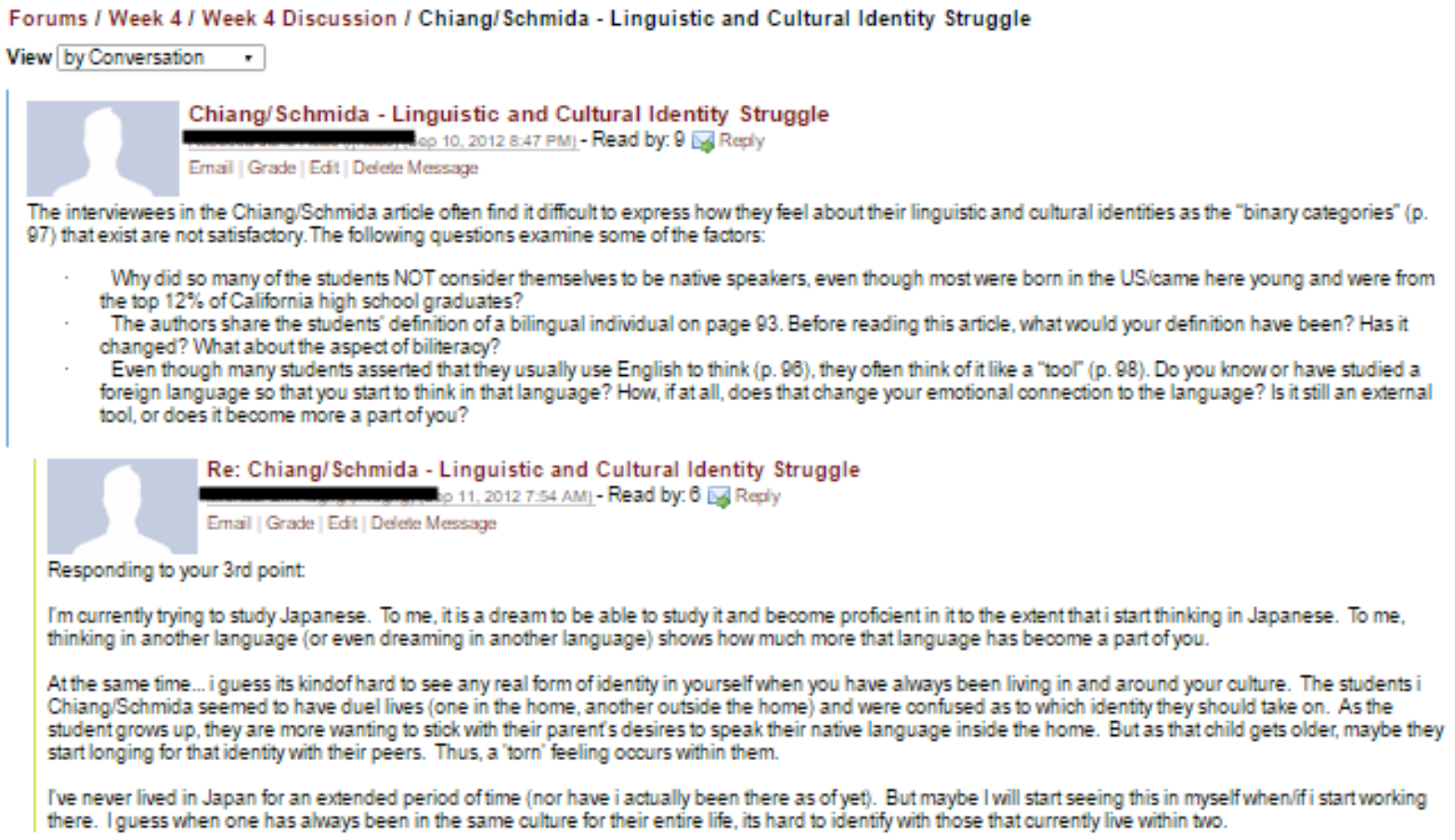

Figure 1. Sequence organization in the AOD

\section{Methods}

The goal of this paper was to explore how participants negotiate and discursively manage the roles assigned to them as part of their online class participation. Findings reported here come out of data gathered for a larger study and look specifically at the roles of Discussion Starter and Devil's Advocate to understand: (a) How do participants take up assigned roles in the online class forum discussions? and (b) How is participants' orientation to these roles made visible in their posts?

\section{Context}

Data were gathered from a master's-level online teacher education course at a large Midwestern university. The course content included readings from two main texts and occasional supplemental articles related to the content of the course. The readings served as the foundation for asynchronous forum discussions that took place weekly.

After the first week of the semester participants were assigned roles such as Discussion Starter or Devil's Advocate, designed to encourage a learner-centered online classroom (Hara et al., 2000) by asking the learners to take responsibility for the direction of the discussion. Discussion was required to be based on the readings, but what was introduced for discussion was within the purview of the participants. The subsequent unfolding of the discussion was an interactive dialogue between all participants, including the instructor. The roles were established in the syllabus for the course, which briefly outlined expectations for each role, including deadlines for posting for select roles (see Appendix A). 


\section{Participants}

Participants included 10 students (two preservice and eight inservice teachers) and the instructor of record (the researcher). The teaching experience of the participants ranged from 0-30 years and included a mix of full-time graduate students and current practicing teachers in K-12 and tertiary settings in the US. All students had previously taken at least one online class. Pseudonyms have been used to identify each participant.

\section{Data Collection}

After approval from the institutional review board, data were downloaded as text files (txt). The data were collected after the conclusion of the course, the researcher/instructor was not the one who solicited consent to participate and was not informed about who agreed or did not agree to participate in the study. A custom-developed script used the UNIX command sed to globally replace usernames, nicknames, familiar names, and locations with pseudonyms across all files in the data set (Warren \& Pfaffman, 2016). These text files were then uploaded into ATLAS.ti (version 7) for analysis. Thus, data were anonymized before the researcher began analysis, further ensuring the protection of the participants.

\section{Analytical Procedures and Warranting Analytic Claims}

CA was used as the framework for the study. To understand what participants were accomplishing in their interactions, as well as how they were accomplishing it, this study draws upon CA's focus on sequence analysis (Sacks, 1992). This analytical approach enabled attention to how participants' orientation to their assigned roles was made visible in their posts. It was also useful in making sense of how other members of the class responded to these posts by attending to the ways in which their responses were situated in the ongoing interaction and designed to accomplish particular social actions (action-oriented).

Analytical interest was focused on the Discussion Starter and Devil's Advocate roles as these were the two "leadership" positions assigned within the AODs each week. To understand participant orientation to these assigned roles, a first round of coding was used to identify any posts that were identified by their authors as either a Discussion Starter or Devil's Advocate post. Any post adjacent to posts identified as enacting either of these roles was also included in the final dataset (i.e., appearing after it or before it within a threaded series of posts). Finally, the data were read once more to identify any additional posts which were not adjacent but specifically referred to the Discussion Starter or Devil's Advocate posts, either by direct mention of that weeks' role enactor or by indirect mention of the post, such as "thanks for the provocative questions, Doris" or "in response to your devil's advocate question...." These data were marked for inclusion in the dataset through the use of the "code" feature in ATLAS.ti and a secondary file containing only relevant posts was created. In all, 26 conversational threads were begun by participants enacting the Discussion Starter role, and each subsequent post within these initial threads were included in the analysis (1061 individual posts). Within this, 47 posts were categorized as enacting the Devil's Advocate role (either by the use of a devil emoji or by use of the phrase itself), while the surrounding posts were important for making sense of how participants oriented to each role sequentially within the data.

Following this initial round of coding, analysis was iterative, with each successive phase focused on identifying how each post within the forum was constructed as a response to something else (e.g., first and second turn parts), as well as the internal design of each post, in order to 
understand a) the relationship of each post to the overall context of the forum and b) the ways that participants oriented to the role assignments within a post as well as the social actions being accomplished. This involved recursive reading and memo-writing. In keeping with a CA approach, memos were focused on what language was used (i.e., what conversational moves participants made), as well as how participants positioned the roles of Discussion Starter and Devil's Advocate within their posts. That is, analytic focus was both on what was being accomplished interactionally, as well as how it was being accomplished by participants' linguistic choices (Hutchby \& Wooffitt, 2008). The focus on conversational features (i.e., claims of knowing or not knowing) worked to "characterize the action" (Seedhouse, 2004, p. 40) of enacting the assigned roles within the sequences of interaction in the AOD. Finally, each post was re-examined in the context of the original datasets following next-turn proof procedure (Sacks, Schegloff, \& Jefferson, 1974) to ensure that the analytic claims were situated within the interactional context of the AOD. The lineby-line analysis presented in the findings lays bare the analytic process-- serving as a warrant for analytic claims and inviting the reader to serve as co-analyst and to draw their own conclusions regarding the data. Finally, analytic claims are grounded in existing research, as any qualitative approach requires that empirical grounding be provided for "any description to be accepted as valid" (Peräkylä, 1997, p. 202).

\section{Participant Uptake of Assigned Roles}

\section{Results}

Findings from the microanalysis of online discussions are reported in this section. Findings related to each role are described separately before considering patterns in the findings as a whole.

\section{Posting as Discussion Starter}

Discussion starters were instructed to begin each week with a question or set of questions related to the week's readings. In the AODs, questions typically were followed by more than one response. Evidence for the way that the Discussion Starters' initial posts worked to frame possibilities for discussion and were taken up by members of the class is presented in Extract 1.

\section{Extract 1}

Author: Doris

Date: Sep 24, 10:25 AM

Subject: Discussion Starter Question for "Opening Our Doors...”

One of the biggest challenges that college instructors face, at least at the freshman level, is convincing students that not all writing looks like a 3.5 academic essay (Basically five paragraphs with an introduction, conclusion, and three body paragraphs). [lines omitted

If the SA approach were used more often in the elementary, middle, and high schools, how would these lessons allow students to be more successful in their writing at the college level? Do any of you use these strategies to 'motivate' your students to invest in their writing and appreciate each individual writing situation? OR are you restricted from doing these types of inventive lessons because you have to prepare students for the essay prompt scenario that will be on the end-of-the-year assessment? 
Author: Belinda

Date: Sep 24, 11:42 AM

Subject: Re: Discussion Starter Question for "Opening Our Doors..."

Doris,

After our readings this week, and learning more about the SA approach, I could see the benefits of this approach for all students. Analyzing the writing in my building, I believe teachers are anxious about not following the plan. Going beyond the traditional five paragraph essay is not in the curriculum, and definitely not what the students will see on the [state standardized exam].

As typical across the dataset, the Discussion Starter post in Extract 1 begins with several statements framed as facts. These statements work to orient other participants to the coming question, creating a context for the presented topic of the "SA approach." These statements, further, work to position the context that "college instructors face" regarding "convincing students that not all writing looks like a 3.5 academic essay" as a dilemma to be solved-- perhaps by the "SA approach."

This opening achieves several interactional accomplishments, including "setting the stage" for the ensuing discussion, which, unlike in an elective setting (such as an online help forum) the participant who made the initial post can be fairly certain will unfold. By beginning with an account of EL students learning to write, Belinda's description works to manage the range of possibilities on which co-participants may draw when crafting their responses. Descriptions in action depend on the "selective management of the realm of objects and events that are to be considered" (Potter, 1996, p. 111-112). That is, by selectively managing the description of EL students in her own post, Belinda's post provides a range of possible constructions from which subsequent participants may draw in presenting their own descriptions. Additionally, it is clear in this original post (OP) that the student has designed her post specifically for her co-participants, whom she collectively addresses through the pronoun "you" in posing her questions. Thus, the design of the turn establishes a purpose for discussion, assigns accountability to her co-participants through directly, though not specifically, asking for their experience, and - at least potentiallydelimits the positions from which co-participants may respond.

Belinda's uptake of Doris's question in the next post ratifies the question as worthy of an answer. From a conversation analytic standpoint, it functions a topic acceptance move, in which a respondent (Belinda) accepts the topic proposed by another participant (Doris) as appropriate and worthy of discussion. Further, Belinda's response hews closely to topics presented in Doris' original post. From a CA perspective, this topic alignment may be viewed as a serving an affiliative function; that is, it aligns the second participant socially with the first (Lindström \& Sorjonen, 2013). This affiliative move functions to confirm the position taken in the first post-- that the types of essays taught in K-12 classrooms do not adequately prepare students for college and that the "SA approach" might better serve students, were it not for state mandated tests. Agreement (rather than disagreement) has been documented empirically as "preferred" in everyday and in academic social interaction (Lester \& Paulus, 2011; Pomerantz, 1984). Thus, although respondents to this question could potentially disagree with the categorization that has been set up, expectations for social accountability suggest that this would have been the more unlikely response. 


\section{Posting as Devil's Advocate}

Across the 14 weeks of discussion, analysis found that participants explicitly identified their posts as a Devil's Advocate post 47 times. Given that each week, only one student was assigned this role, each post was examined individually to determine how this identification was being used. This revealed that within 7 of the 14 weeks, participants assigned as Devil's Advocate made more than one post, while in the other weeks, these posts were made by participants not assigned this role. Participants identified the use of this role both through words (e.g., writing "this is a bit of a devil's advocate question, but...") and through the use of a devil emoji provided within the word processing mechanism in the forum (영). The use of this devil emoji was the preferred pattern, but only slightly, with 27 instances of the emoji and 20 instances of the phrase Devil's Advocate identified.

Orienting to the role of Devil's Advocate. Devil's Advocate posts and subsequent posts within the conversational thread were examined to determine whether and how participant orientation to the role of Devil's Advocate was made visible in their posts. For this, the focus was both on the way the student posting as the Devil's Advocate organized their own post, as well as how their classmates oriented to this role in their responses. The line-by-line analysis presented here demonstrates how participants commonly oriented to this assigned role.

\section{Extract 2}

Author: Jennifer

Date: Sep 11, 8:22 AM,

Subject: Re: Ibrahim - The reflection of society's mirror

For the sake of conversation, How involved should we get with our students? With everything going on today, shouldn't we make sure to keep student relationships very professional? They are the student, and we are the educator, should our roles stop there? It is very consuming and emotional to take the part as caregiver, supporter, and invest in our students. Where is the line and how do we make sure we do not cross it?

Author: Lia

Date: Sep 11, 12:15 PM

Subject: Re: Ibrahim - The reflection of society's mirror

I am with you one hundred percent. I have had students come in and say they had nowhere to sleep the night before and could they just sit for a second before starting on the day's activities. They are also extremely vulnerable. I had a student last year who liked me and another teacher so much that she chose to go to our alma mater.

The involvement with students is always a touchy subject. I think one thing we have to make sure of is that we are understanding what they want us to hear while also toeing the line as far as reporting information as far as a legal matter goes...

Here, Jennifer makes her role as Devil's Advocate immediately visible to the rest of the participants in the group by her use of the devil emoji. By using the emoji to mark her enactment of the Devil's Advocate role, Jennifer makes visible her "right"--at least potentially--to pose questions to the group. As evident in the response to the original question by the Devil's Advocate in Extract 3, the assumed right of posing questions is ratified by Lia's immediate uptake of the question posed by Jennifer in the subsequent posting. As demonstrated here, across the dataset posts by the Devil's Advocate were understood to demand a response. 
Across the dataset, use of the devil emoji also worked to demarcate the coming topic as potentially controversial or provocative. Relatedly, participants enacting this role were found to distance themselves from the role through their conversational moves. In the example extract here, the vague introductory clause, "with everything going on today" serves to introduce a potentially controversial topic to the group while it simultaneously avoids categorizing what, specifically, might be going on. The vagueness of the introductory clause provides Jennifer "plausible deniability" (Auburn \& Lea, 2003) with regard to any specific knowledge of the issues despite introducing the topic in her post. Jennifer's post further distances herself from specific knowledge regarding this topic by providing a categorization of how teachers should act through her description of "keep[ing] student relationships very professional." This occasioning of a categorical predicate, or the actions exhibited by members of the category (Sacks, 1992), suggests a set of behaviors that are appropriate for teachers and implies that other behaviors would not be appropriate. Thus, although Jennifer has introduced a controversial topic in her post, the categorization that follows functions as a distancing move, allowing Jennifer to avoid claiming personal knowledge of the topic.

Lia's uptake of Jennifer's positioning of teachers as needing to keep relationships "very professional" is visible through Lia's echoing of Jennifer's skepticism toward getting "involved" with their students. The provision of additional examples from her own experience ratifies this stance (Goodwin \& Heritage, 1990), solidifying the description of teacher-student relationships as "very professional," as the appropriate stance to take. Although positioning oneself as adopting a professional stance is not in itself a surprising position, nevertheless, these participants spent a good deal of their AOD posts iterating its importance. This analysis demonstrates how, upon the introduction of potentially controversial topics, participants worked to immediately distance themselves from becoming associated with these positions.

Doing "being critical" in the role of Devil's Advocate. Extract 3 illustrates how the role of Devil's Advocate was used by students to take a critical stance toward the positions of others within the AOD.

\section{Extract 3}

Author: Doris

Date: Sep 18, 6:55 PM

Subject: Re: Should we invite students to write in home languages?

It depends on the purpose of the writing. If the purpose is to be graded and to determine mastery of standards than it should be written in English. However, if the purpose is notetaking or personal lists/materials, that will not be graded or does not serve a purpose to anyone other than the writer, then I do not see the problem in allowing them to write in their home language. In addition, i would be open to accepting a letter written in home language if the letter served a purpose and was actually sent out. There are many contacts available in the area that would be able to translate and check for accuracy of the message contained in the letter.

Author: Hannah

Date: Sep 19, 9:57 PM

Subject: Re: Should we invite students to write in home languages? 
I'm not in the Devil's Advocate role this week, but I'm gonna play it for a minute. I'm wondering if your distinctions here...if it's grade and formally displays mastery of standards then it's in English and if it's informal note-taking then it can be in your L2...creates a negative connotation with the student's L2. Like, my L2 is not 'worthy' or I can only ever use my L2 in these specific situations. Bean et. al talks about the importance of increasing "students' ownership and investment in writing" (p. 229). Does what you're describing do that? Or am I overthinking this? I could totally see how maybe I'm overlooking the fact that these are ELL classes...maybe not bilingual classes... and the main goal here is to learn English so obviously, we're going to do A LOT of writing in English.

As illustrated in this post, participants took up the Devil's Advocate position as one of critique, even when they were not assigned the role. In her post, Hannah directly critiques positions toward occasions for writing in students' home languages proposed by Doris in the previous post. Disagreement is understood by conversation analysts as a socially "dispreferred" response (Pomerantz, 1984, p. 83). In other words, within typical social interactions, the expected social response is for agreement. In academic settings too, agreement has been found to be the typical response (e.g., Lester \& Paulus, 2011). Thus, participants took up the Devil's Advocate role as a means of enacting disagreement with others in the forum, perhaps as a way of distancing themselves personally from what might be an otherwise socially difficult position to enact.

Doing "being a novice" in Devil's Advocate posts. Analysis also found that participants used the mantle of Devil's Advocate as a way of asking questions on topics with which they were unfamiliar.

\section{Extract 4}

Author: Neill

Date: Nov 14, 9:55 PM

Subject: Re: Best strategies for teaching text structures

I I think one of the fun things about playing devil's advocate when you have no teaching experience is that there tend to be a lot of things that don't make sense and require an explanation :D

So a general question for now:

This chapter gave a lot of REALLY useful information regarding exercises and tools to help make the learning procedure meaningful to the student. I will in no way argue against that. However, is there ever a point where too much variety can be unsettling to a student? Would it be better to choose a handful of procedures at a time and use them until the students get 'bored' of it or start to anticipate it and then switch?

In this extract, Neill begins his post by explicitly positioning the Devil's Advocate role as "fun" because it offered a chance to ask questions about "things that don't make sense and require an explanation." Positioning the Devil's Advocate role as one which enables participants to ask even "general question[s]" establishes Neill's "right" to ask what might otherwise be oriented to as a known answer or non-question. That is, by establishing his lack of teaching experience at the start of the post, Neill allays potential criticism of the question that he has posed by taking up an epistemic stance (i.e., expression of knowledge) (Heritage, 2012a) of a relative novice. 


\section{Extract 5}

Author: Elizabeth

Date: Sep 11, 4:11 PM

Subject: Re: Ibrahim - The reflection of society's mirror

영 I know in elementary school, we do a lot of journal writing and free writes, but what about in higher grades? To piggy back on what Doris said, where do you draw the line on what is appropriate to write about? What about the language they use?

Extract 5 provides another example of marking a post as specifically enacting the role of Devil's Advocate, while asking what appears to be a genuine, though not overtly critical, question. In this post, Elizabeth marks her status as an elementary school teacher who is not aware of the practices appropriate in higher grades. Elizabeth then couches her question as "piggy back[ing]" on what another participant had said regarding appropriate writing topics. Interestingly, this positions her coming questions as being asked both from a position of not knowing and as coming, at least in part, from another participant's words. The questions, then, are marked as not entirely her own, but as the result of her unfamiliarity with the practices of "higher grades" and her classmate's previous post.

\section{Discussion}

Analysis revealed that within the weekly discussion, an overall pattern of question-answer sequences set up the conditions for participation in this institutional setting. Questions typically were followed by more than one response, a notable difference between the typical initiateresponse-feedback pattern of face-to-face classroom discussions, in which a teacher initiates a question, a student responds, and the teacher offers evaluation or feedback related to the response (Cazden, 1988; Sinclair \& Coulthard, 1975). With respect to the role of Devil's Advocate, it was found that participants most often oriented to this role as a kind of secondary Discussion Starter, often posing questions on topics tangential to the original discussion post. Thus, findings demonstrate how assigned discussion roles and the enactment of these roles established an overall pattern of question-answer sequences that served as a "participation framework" (Goffman, 1974; Stommel \& Koole, 2010), reinforcing the interactional framework of the forum and delimiting possibilities for interaction.

Previous research has found that students valued the direction provided by the Discussion Starter role (Wise, Saghafian, \& Padmanabhan, 2012). While participants' uptake of the stances and topics introduced by the Discussion Starter demonstrates that these posts do establish a direction for the ensuing discussion, the micro-analytic approach taken in this study demonstrates that the questions posed in the Discussion Starter posts may also limit possibilities for divergence. Given the inclination toward agreement, rather than disagreement in social interaction in general (Pomerantz, 1984) and in educational contexts (Lester \& Paulus, 2011), which was also frequently displayed by the students in this study, it may be that these questions influence the direction of conversation even more than originally thought.

Analysis of the Devil's Advocate role showed that this role could be used by students to enable disagreement that would otherwise be unexpected or outside the norms of conversation. It has been argued that the role of "Devil's Advocate implies a criticality that gives learners 'permission' to challenge their classmates" (Wise, Saghafian, \& Pradmaban, 2012, p. 77). The 
findings from the present study shore up this finding. Participants were observed to use the mantle of Devil's Advocate when disagreeing with each other, even at times when they were not assigned the role. This study also found that posts classified as enacting the role of Devil's Advocate included cases of the participants distancing themselves from the claims in their post. That is, in posts where participants positioned themselves as enacting the role of Devil's advocate, participants also worked to minimize their accountability for the content of these posts and thereby manage their stake in the task itself (Potter, 1996). This was most often evident when participants distanced themselves from knowledge of the topic of the posts, as in Extracts 1 and 5. However, this "stake inoculation" (Potter, 1996, p. 124) sometimes occurred when participants distanced themselves from the action in the posts, as in Extract 3. That is, participants minimized being held personally accountable for the content of the Devil's Advocate postings by distancing themselves from the action the post performed, taking up the mantle of Devil's Advocate to enact the otherwise socially dispreferred action of disagreement.

Second, this study found that participants sometimes used the role of Devil's Advocate to ask genuine questions that might otherwise have gone unasked. When someone asks a genuine question, it is because their epistemic stance is congruent with the epistemic status. That is: The questioner is unable to provide the requested piece of information (Heritage 1984; Heritage 2012a; Heritage 2012b). Particularly for students who had less experience as teachers than others in the course, the mantle of Devil's Advocate gave these participants permission to pose questions not from a critical stance, but from a novice one. This unforeseen use of the role has implications for its use in AODs. It may be that this role also gives learners "permission" to ask questions that they might otherwise be afraid to ask. Conversely, it may be that participants' use of their novice status afforded them the opportunity to avoid taking up a more critical stance within the discussion. One function of claiming "no access to, or insufficient knowledge of" the topic at hand is that it enables participants to decline a request (Pomerantz, 1984, p. 57). In this case, invocation of their novice status may have functioned to enable participants to decline adopting the role as defined in the participation guidelines (Appendix A). In other words, by asking a genuine question, they avoided the dispreferred action of posing a critical one.

\section{Limitations and Implications for Further Study}

Consistent with the analytical approach used in this study, findings are not meant to be generalized, but are illustrative of the uptake of assigned discussion roles within a particular interactional context. In particular, the findings of this study were affected by the affordances of the learning management system (LMS), which offered emoji as a mode of communication. Additionally, participants in this course were graduate-level students who had all taken at least one asynchronous online course before. However, the study did not analyze participants' construction of assigned discussion roles across previous online courses to look for whether students' previous experiences impacted their orientation toward the roles. Therefore, it is not possible to draw conclusions regarding whether these students' use of assigned participation roles might look different in a different context.

CMC researchers have observed that participants in online dialogues draw upon their knowledge of existing genres when dialogue moves online (Ferrara, Brunner, \& Whittemore, 1991; Lapadat, 2007). In the present data, interaction was indeed observed to follow patterns of talk recognizable as educational or classroom discourse. By examining how the participants in the course oriented to particular roles within the discussion, however, it was found that these discussions were characterized, at times, by conversational moves designed to distance participants 
from the proscribed guidelines for these roles. Instructional implications include the need to acknowledge that while asking students to enact particular roles may indeed encourage engagement, students may not always feel comfortable in such roles. Particularly when the expectations for such roles may be deemed controversial, students may take up interactional practices which allow them to distance themselves or otherwise avoid fully enacting the roles as designed. Thus, effective planning should consider when such roles may be useful, and when they may encroach upon broader educational goals. 


\section{References}

Auburn, T., \& Lea, S. (2003). Doing cognitive distortions: A discursive psychology analysis of sex offender treatment talk. British Journal of Social Psychology, 42, 281-298.

Baym, N. K. (1996). Agreements and disagreements in a computer-mediated discussion. Research on Language and Social Interaction, 29(4), 315-345. doi:10.1207/s15327973rlsi2904_2

Ben-Peretz, M., \& Kupferberg, I. (2007). Does teachers' negotiation of personal cases in an interactive cyber forum contribute to their professional learning? Teachers and Teaching, 13(2), 125-143. doi:10.1080/13540600601152462

Brooks, C. F. (2013). 'Don't even trip, u did your part': Analyzing community in online student talk. Classroom Discourse, 4(2), 168-189. doi:10.1080/19463014.2013.823349

Cazden, C. B. (1988). Classroom discourse. The language of teaching and learning. Portsmouth, NH: Heinemann.

Ferrara, K., Brunner, H., \& Whittemore, G. (1991). Interactive written discourse as an emergent register. Written Communication, 8(1), 8-34. doi:10.1177/0741088391008001002

Fisch, A. A., \& Bennett, D. J. (2011). Independence and interdependence: An analysis of pre-service candidates' use of focused assignments on an electronic discussion forum during the initial field experience. Interdisciplinary Journal of Teaching and Learning, 1(1), 23-42.

Garfinkel, H. (1967). Studies in ethnomethodology. Englewood Cliffs, NJ: Prentice Hall.

Giles, D., Stommel, W., Paulus, T., Lester, J., \& Reed, D. (2015). Microanalysis of online data: The methodological development of "digital CA". Discourse, Context \& Media, 7, 45-51. https://doi.org/10.1016/j.dcm.2014.12.002

Goertzen, P., \& Kristjánsson, C. (2007). Interpersonal dimensions of community in graduate online learning: Exploring social presence through the lens of systemic functional linguistics. The Internet and Higher Education, 10(3), 212-230. http://dx.doi.org/10.1016/j.iheduc.2007.06.005

Goffman, E. (1974). Frame analysis: An essay on the organization of experience. New York: Harper.

Goodwin, C., \& Heritage, J. (1990). Conversation analysis. Annual Review of Anthropology, 19, 283-307. https://doi.org/10.1146/annurev.an.19.100190.001435

Hara, N., Bonk, C. J., \& Angeli, C. (2000). Content analyses of on-line discussion in an applied educational psychology course. Instructional Science, 28(2), 115-152. doi:10.1023/A:1003764722829

Heritage, J. (2012a). Epistemics in action: Action formation and territories of knowledge. Research on Language \& Social Interaction, 45(1), 1-29. https://doi.org/10.1080/08351813.2012.646684

Heritage, J. (2012b). The epistemic engine: Sequence organization and territories of knowledge. Research on Language \& Social Interaction, 45(1), 30-52. https://doi.org/10.1080/08351813.2012.646685

Heritage, J. (1984). A change-of state token and aspects of its sequential placement. Structure of Social Action: Studies in Conversation Analysis, 299-345.

Hmelo, C. E., Guzdial, M., Turns, J. (1998). Computer-support for collaborative learning: Learning to support student engagement. Journal of Interactive Learning,9(2), 107-129.

Hou, H. (2015). What makes an online community of practice work? A situated study of Chinese student teachers' perceptions of online professional learning. Teaching and Teacher Education, 46(Supplement C), 6-16. https://doi.org/10.1016/j.tate.2014.10.005 
Hutchby, I., \& Tanna, V. (2008). Aspects of sequential organization in text message exchange. Discourse \& Communication, 2(2), 143-164.

Hutchby, I., \& Wooffitt, R. (2008). Conversation analysis. Cambridge, UK: Polity Press.

Jones, M., \& Ryan, J. (2014). Learning in the practicum: Engaging pre-service teachers in reflective practice in the online space. Asia-Pacific Journal of Teacher Education, 42(2), 132-146. doi:10.1080/1359866X.2014.892058

Killeavy, M., \& Moloney, A. (2010). Reflection in a social space: Can blogging support reflective practice for beginning teachers? Teaching and Teacher Education, 26(4), 1070-1076. doi:10.1016/j.tate.2009.11.002

Knowlton, D. S. (2005). A taxonomy of learning through asynchronous discussion. Journal of Interactive Learning Research, 16(2), 155-177.

Krutka, D. G., Bergman, D. J., Flores, R., Mason, K., \& Jack, A. R. (2014). Microblogging about teaching: Nurturing participatory cultures through collaborative online reflection with pre-service teachers. Teaching and Teacher Education, 40, 83-93. http://dx.doi.org/10.1016/j.tate.2014.02.002

Lamerichs, J., \& te Molder, H. F. M. (2003). Computer-mediated communication: From a cognitive to a discursive model. New Media \& Society, 5(4), 451-473. doi:10.1177/146144480354001

Lapadat, J. C. (2007). Discourse devices used to establish community, increase coherence, and negotiate agreement in an online university course. The Journal of Distance Education/Revue de l'Éducation à Distance, 21(3), 59-92.

Lester, J. N., \& Paulus, T. M. (2011). Accountability and public displays of knowing in an undergraduate computer-mediated communication context. Discourse Studies, 13(6), 671-686. doi:10.1177/1461445611421361

Levin, B. B., He, Y., \& Robbins, H. H. (2006). Comparative analysis of preservice teachers' reflective thinking in synchronous versus asynchronous online case discussions. Journal of Technology \& Teacher Education, 14(3), 439-460.

Lindström, A., \& Sorjonen, M. A. (2013). Affiliation in conversation. In J. Sidnell and T. Stivers (Eds.) The handbook of conversation analysis (350-369). West Sussex, UK: Wiley Blackwell.

Loncar, M., Barrett, N. E., \& Liu, G. Z. (2014). Towards the refinement of forum and asynchronous online discussion in educational contexts worldwide: Trends and investigative approaches within a dominant research paradigm. Computers \& Education, 73, 93-110.

Meredith, J. (2017). Analyzing technological affordances of online interactions using conversation analysis. Journal of Pragmatics, 115, 42-55. https://doi.org/10.1016/j.pragma.2017.03.001

Olesova, L., Slavin, M., \& Lim, J. (2016). Exploring the effect of scripted roles on cognitive presence in asynchronous online discussions. Online Learning, 20(4), 34-53.

Paulus, T. M., Warren, A. N., \& Lester, J. L. (2016). A conversation analytic approach to online talk: A literature review. Discourse, Context \& Media, 12, 1-10. http://dx.doi.org/10.1016/j.dcm.2016.04.001

Peräkylä, A. (1997). Reliability and validity in research based on tapes and transcripts. In D. Silverman (Ed.), Qualitative research: Theory, method and practice (201-220). London: Sage.

Pomerantz, A. (1984). Agreeing and disagreeing with assessments: Some features of preferred/dispreferred turn shapes. In J. M. Atkinson \& J. Heritage (Eds.), Structures of social action (pp. 57-101). Cambridge, UK: Cambridge. 
Navigating Assigned Roles for Asynchronous Online Discussions:

Examining Participants' Orientation Using Conversation Analysis

Potter, J. (1996). Representing reality: Discourse, rhetoric and social construction: Sage

Ravenna, G., Foster, C., \& Bishop, C. (2012). Increasing student interaction online: A review of the literature in teacher education programs. Journal of Technology and Teacher Education, 20(2), 177-203.

Rintel, E. S. (2010, November). Conversational management of network trouble perturbations in personal videoconferencing. In Proceedings of the 22nd Conference of the Computer Human Interaction Special Interest Group of Australia on Computer-Human Interaction (pp. 304-311). ACM.

Sacks, H. (1992). Lectures on conversation. Oxford: Blackwell.

Sacks, H., Schegloff, E. A., \& Jefferson, G. (1974). A simplest systematics for the organization of turntaking for conversation. Language, 696-735.

Schegloff, E. A. (2007). Sequence organization in interaction (Vol. 1). Cambridge, UK: Cambridge University Press.

Seedhouse, P. (2004). Conversation analysis methodology. Language Learning, 54(1), 1-54. https://doi.org10.1111/j.1467-9922.2004.00268.x

Sinclair, J., \& Coulthard, M. (1975). Towards an analysis of discourse: The language of teachers and pupils: London: Oxford University Press.

Stahl, G., Cress, U., Ludvigsen, S., \& Law, N. (2014). Dialogic foundations of CSCL. International Journal of Computer-Supported Collaborative Learning, 9(2), 117-125. doi: 10.1007/s11412014-9194-7

Stivers, T. \& Sidnell, J. (2013). Introduction. In. J. Sidnell \& T. Stivers (Eds.). The handbook of conversation analysis. (pp. 1-8). Chichester, West Sussex, UK: Wiley-Blackwell.

Stommel, W., \& Koole, T. (2010). The online support group as a community: A micro-analysis of the interaction with a new member. Discourse Studies, 12(3), 357-378. doi:10.1177/1461445609358518

Strijbos, J. W., Martens, R. L., Jochems, W. M. G., \& Broers, N. J. (2004). The effect of functional roles on group efficiency: Using multilevel modeling and content analysis to investigate computersupported collaboration in small groups. Small Group Research, 35, 195-229.

Swan, K. \& Shea, P. (2005). The development of virtual learning communities. In. S. R. Hiltz, \& R. Goldman (Eds.), Asynchronous learning networks: The research frontier (pp. 239-260). New York: Hampton Press.

Tagg, A. C. (1994). Leadership from within: Student moderation of computer conferences. American Journal of Distance Education, 8(3), 40-50.

Tseng, F. C., \& Kuo, F. Y. (2014). A study of social participation and knowledge sharing in the teachers' online professional community of practice. Computers \& Education, 72(Supplement C), 37-47. https://doi.org/10.1016/j.compedu.2013.10.005

Warren, A. N. \& Pfaffman, J. A. (April 2016). Documenting the undocumented trail: The hidden process of changing CMC into data. Paper presented at the American Education Research Association, Washington, DC.

Weinberger, A., \& Fischer, F. (2006). A framework to analyze argumentative knowledge construction in computer-supported collaborative learning. Computers \& Education, 46(1), 71-95.

Whipp, J. L. (2003). Scaffolding critical reflection in online discussions: Helping prospective teachers think deeply about field experiences in urban schools. Journal of Teacher Education, 54(4), 321333. doi: $10.1177 / 0022487103255010$ 
Wilkinson, S., \& Kitzinger, C. (2006). Surprise as an interactional achievement: Reaction tokens in conversation. Social Psychology Quarterly, 69(2), 150-182. https://doi.org/10.1177/019027250606900203

Williams, K. M., Park, J. H., Gaines, R. E., Choi, E., Lee, J. J., Mattar, L. I., \& Schallert, D. L. (2016). "I wonder if ...": The process of inquiry in support of students' co-learning from online discussion. Literacy Research: Theory, Method, and Practice, 65(1), 365-383. doi:10.1177/2381336916661515

Wise, A. F., \& Chiu, M. M. (2014). The impact of rotating summarizing roles in online discussions: Effects on learners' listening behaviors during and subsequent to role assignment. Computers in human behavior, 38(Supplement C), 261-271. https://doi.org/10.1016/j.chb.2014.05.033

Wise, A. F., Speer, J., Marbouti, F., \& Hsiao, Y. T. (2013). Broadening the notion of participation in online discussions: examining patterns in learners' online listening behaviors. Instructional Science, 41(2), 323-343. doi: 10.1007/s11251-012-9230-9

Wise, A. F., Perera, N., Hsiao, Y. T., Speer, J., \& Marbouti, F. (2012). Microanalytic case studies of indivilual participation patterns in an asynchronous online discussion in an undergraduate blended course. The Internet and Higher Education, 15(2), 108-117. https://doi.org/10.1016/j.iheduc.2011.11.007

Wise, A. F., Saghafian, M., \& Padmanabhan, P. (2012). Towards more precise design guidance: Specifying and testing the functions of assigned student roles in online discussions. Educational Technology Research and Development, 60(1), 55-82.

Xie, K., Yu, C., \& Bradshaw, A. C. (2014). Impacts of role assignment and participation in asynchronous discussions in college-level online classes. The Internet and Higher Education, 20(Supplement C), 10-19. https://doi.org/10.1016/j.iheduc.2013.09.003

Yuan, J., \& Kim, C. (2014). Guidelines for facilitating the development of learning communities in online courses. Journal of Computer Assisted Learning, 30(3), 220-232. doi:10.1111/jcal.12042 


\section{Appendix A}

Participation guidelines provided to students in each section of the online class.

\section{PARTICIPATION GUIDELINES:}

- For each discussion, you will be assigned one of the following roles: reading summary provider, Discussion Starter, Devil's Advocate, or discussion wrapper (at different times in the semester): Reading Summary Provider: Your job is to summarize the main points of the reading. This needs to be posted by Monday at midnight EST. The point of this role is to provide an overview, not reiterate each point of the reading.

- Discussion Starter: You begin our online discussion by asking 1-2 well-thought out questions based on our readings. The best questions to ask are open-ended, and are just meant to get us all talking! Please post discussion questions by Monday at midnight EST.

- Devil's Advocate: You get to ask the questions no one wants to ask. You are the person who gets to turn the conversation its ear by asking a well-timed question that reveals another way of looking at the issue at hand.

- Discussion Wrapper: Examine your position in relation to what's been said in the discussions throughout the week. How has your position changed or grown? How has what you said changed others? Connect your thinking to the readings and discussions for the week. Please post discussion warp-up by Saturday at midnight EST.

**Each person must post a minimum of 4 times over the week. This means that in addition to fulfilling your role, each person is responsible for continuing the discussion through additional responses. 